\title{
Impact performance of specimens subjected to fatigue loading - experimental investigation
}

\author{
Jakub Göringer ${ }^{\mathrm{a}}$, Marek Foglar, and Pavel Jiříček \\ Czech Technical University in Prague, Faculty of Civil Engineering, 16629 Thakurova 7, Prague 6, Czech Republic
}

\begin{abstract}
The impact performance of reinforced concrete specimens subjected to fatigue loading has not been quantified properly yet. This topic is significant in the field of vehicle impact or similar applications. The paper aims to fill this gap by presenting the on-going experimental program. The paper presents outcomes of the experiments focused on the performance of RC beams subjected to drop-weight impact loading. The behaviour of the beams which were prior to the impact testing subjected to cyclic loading was compared to the behaviour of the beams which were not subjected to cyclic loading.
\end{abstract}

\section{Introduction}

Fatigue is the process of permanent progressive changes in the structure of a material subjected to cyclic loading. The influence of fatigue on changes in material structure and their descriptions have been studied by many authors, e.g. [1,2], but the effect of the matrix damage due to cyclic loading on the behaviour of specimens under impact loading has not been properly quantified yet. The combination of these two effects can be expected especially at the structures of transport infrastructure.

The assessment of the structures for impact loading (vehicles, trains) was already studied e.g. in [3] and is already incorporated into the design standards e.g. EN 1991-1-7 [4], but the assessment approaches do not take into account the material damage due to the loads that occur within the lifetime of the structures. In addition, many of these structures are often located in aggressive environment (e.g. de-icing salts for road maintenance). The phenomenon of chemical deterioration has been extensively investigated with regard to the effect of acid rain on concrete structures in $[5,6]$.

The paper presents an on-going experiment dealing with the combined damage due to cyclic loading and aggressive environment together with the impact loading.

\section{Experimental program}

The experimental program is focused on three deteriorative effects reinforced concrete specimens can be exposed to deterioration due to aggressive environment, cyclic loading and impact loading. The paper presents results of the impact behaviour of the specimens stored in different environments.

\subsection{The reinforced concrete specimens}

Reinforced concrete specimens were designed for the experimental program. The strength class of concrete

\footnotetext{
${ }^{a}$ Corresponding author: jakub.goringer@fsv.cvut.cz
}

C25/30-X0 (with low resistance against aggressive environment) was chosen. The specimens were designed as beams with dimensions of $300 \times 150 \times 1300 \mathrm{~mm}$ (width $\times$ height $\times$ length). The mix proportions of the concrete mixture are provided in Table 1.

The specimens were designed as over-reinforced $(6 \oslash$ 16 grade B500 reinforcing steel), thus a failure by compressive-zone crushing should occur and the fatigue failure of concrete (bending/shear) can be assumed during the cyclic loading. The scheme of specimen reinforcement can be seen in Fig. 1.

The specimens were stored in dry or aggressive environment to allow the determination of the influence of the aggressive environment on the impact behaviour. The specimens were subsequently exposed to cyclic loading.

In total 17 specimens were cast (see Table 2 for the list of the specimens) and three were already tested for impact loading; specimen \#1 - stored in dry condition, not exposed to cyclic loading (R1); specimen \#2 - stored in dry condition, exposed to cyclic loading (C3) and specimen \#3 - stored in acidic environment, exposed to cyclic loading (A7).

\subsection{Aggressive environment}

For the purpose of simulation of the aggressive environment on structures, several specimens were stored in a solution of hydrochloric acid. The acidity of the aggressive environment was chosen according to the exposure classes specified in the European standards, namely EN 206-.

For the acceleration of the chemical deterioration, the solution of hydrochloric acid was maintained with $\mathrm{pH}=$ 2.0. The methodology for the evaluation of the influence of the aggressive environment on the concrete specimens is described in [7].

\subsection{The fatigue testing}

The arrangement of the cyclic loading is the four-point bending test with span length $1000 \mathrm{~mm}$ and overhangs with

This is an Open Access article distributed under the terms of the Creative Commons Attribution License 4.0, which permits unrestricted use, distribution, and reproduction in any medium, provided the original work is properly cited. 
Table 1. Mix proportions of the concrete mixture.

\begin{tabular}{|l|l|}
\hline CEM II 32.5 $[\mathrm{kg} / \mathrm{m} 3]$ & 320 \\
\hline Sand $[\mathrm{kg} / \mathrm{m} 3]$ & 836 \\
\hline Fine aggregate $[\mathrm{kg} / \mathrm{m} 3]$ & 495 \\
\hline Coarse aggregate $[\mathrm{kg} / \mathrm{m} 3]$ & 443 \\
\hline Water $[\mathrm{kg} / \mathrm{m} 3]$ & 185 \\
\hline w/c ratio & 0.58 \\
\hline
\end{tabular}

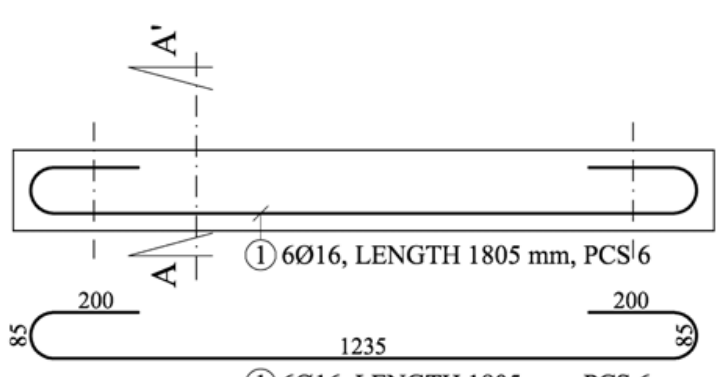

(1) $6 \varnothing 16$, LENGTH $1805 \mathrm{~mm}$, PCS 6

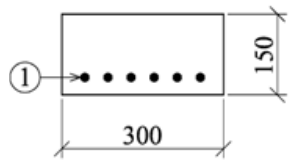

Figure 1. Reinforcement scheme of the specimens.

Table 2. List of all specimen sets.

\begin{tabular}{|c|c|c|c|c|c|c|}
\hline \multicolumn{3}{|c|}{ Dry environment } & \multicolumn{4}{|c|}{ Acidic environment } \\
\hline \multirow{2}{*}{ Spec } & $\begin{array}{c}\text { Cyclic } \\
\text { testing } \\
\text { age }\end{array}$ & $\begin{array}{c}\text { Impact } \\
\text { testing }\end{array}$ & \multirow{2}{*}{ Spec } & $\begin{array}{c}\text { Cyclic } \\
\text { testing } \\
\text { age }\end{array}$ & $\begin{array}{c}\text { Acid } \\
\text { exp. }\end{array}$ & $\begin{array}{c}\text { Impact } \\
\text { testing }\end{array}$ \\
\cline { 2 - 7 } [day] & {$[\mathrm{Y} / \mathrm{N}]$} & & {$[$ day $]$} & {$[$ day $]$} & {$[\mathrm{Y} / \mathrm{N}]$} \\
\hline C1 & 28 & $\mathrm{~N}$ & $\mathbf{A 1}$ & 133 & 7 & $\mathrm{~N}$ \\
\hline C3 & 35 & $\mathrm{~N}$ & $\mathbf{A 2}$ & 182 & 14 & $\mathrm{~N}$ \\
\hline C4 & 42 & $\mathrm{Y}$ & $\mathbf{A 3}$ & 224 & 30 & $\mathrm{~N}$ \\
\hline C5 & 63 & $\mathrm{~N}$ & $\mathbf{A 4}$ & 364 & 60 & $\mathrm{~N}$ \\
\hline C6 & 105 & $\mathrm{~N}$ & $\mathbf{A 5}$ & 406 & 90 & $\mathrm{~N}$ \\
\hline R1 & - & $\mathrm{N}$ & $\mathbf{A 6}$ & 728 & 180 & $\mathrm{~N}$ \\
\hline R2 & - & $\mathrm{N}$ & $\mathbf{A 7}$ & 777 & 360 & $\mathrm{Y}$ \\
\hline & & & $\mathbf{A 9}$ & 1099 & 720 & $\mathrm{~N}$ \\
\hline
\end{tabular}

length of $150 \mathrm{~mm}$. This testing layout has been chosen for its several advantages described in [7].

Experiments are conducted in the Experimental Centre of Faculty of Civil Engineering, Czech Technical University in Prague. The arrangement of the fatigue testing can be seen in Fig. 2, for its parameters see Table 3.

Due to the high time demands of the experiments the maximum number of applied cycles for each specimen is around 400 thousand cycles.

These phenomena mentioned above - cyclic loading and aggressive environment are reflected in the discussion of the behaviour during the impact loading.

\subsection{The impact loading}

For the impact loading, a braced steel frame (Fig. 3) carrying drop weight was built in the Experimental Centre of the CTU. Due to laboratory build-in crane, height of

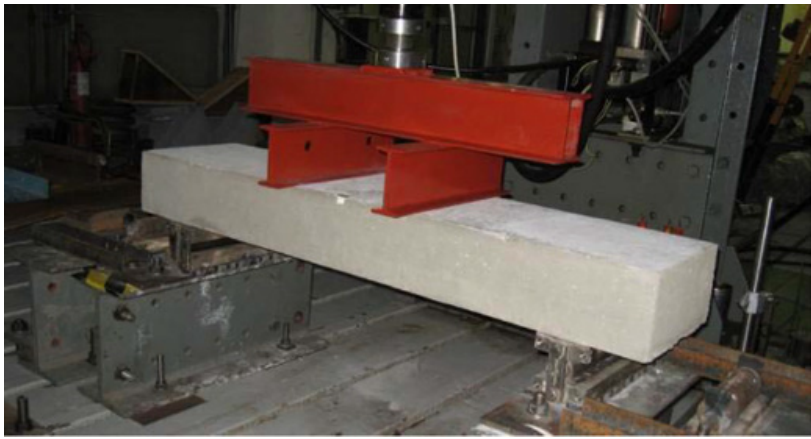

Figure 2. The arrangement of the fatigue testing.

Table 3. Specification of the fatigue testing settings.

\begin{tabular}{|c|c|c|c|}
\hline \multirow[b]{2}{*}{ Loading Frequency } & \multicolumn{2}{|c|}{ Cyclic force } & \multirow{2}{*}{ Eccentricity } \\
\hline & Min & $\max$ & \\
\hline $\mathrm{Hz}$ & \multicolumn{2}{|c|}{$\mathrm{kN}$} & $\mathrm{m}$ \\
\hline 5 & 5 & 100 & 0.3 \\
\hline
\end{tabular}

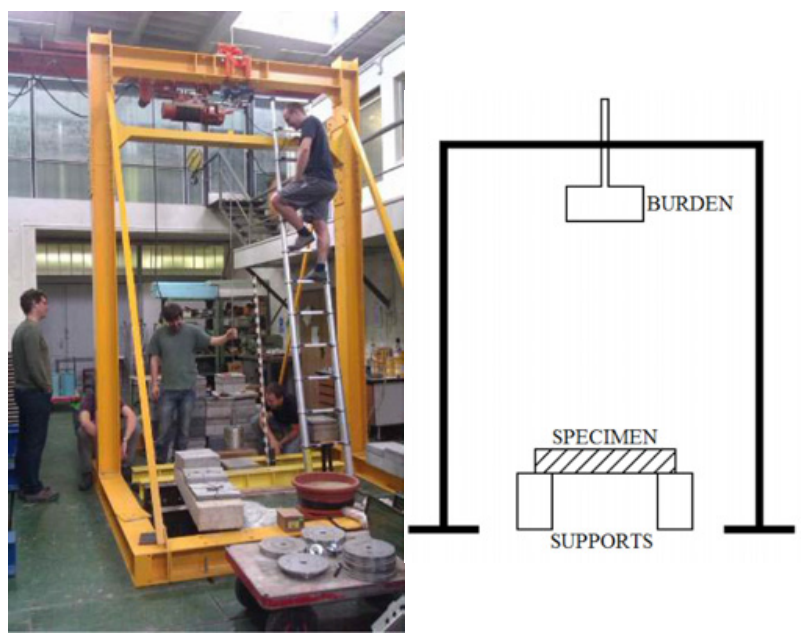

Figure 3. Steel frame and the scheme or the experiment.

the frame is limited to $4.1 \mathrm{~m}$. Horizontal base of the construction is made of steel frame anchored to the floor of the laboratory. Vertical stability is provided by bracing diagonals. The burden is considered as a set of different weights to enable maximal variety of the drop-weight.

The tested concrete specimen is located in the biaxial centre of the horizontal frame. The sample is supported on two parallel sides by reinforced steel girders which were anchored to the floor. To ensure similar layout as in case of the cyclic loading two reinforcing bars were attached to the steel girders. This ensured the span length of $1000 \mathrm{~mm}$ and simple supported beam behaviour. The difference between the cyclic loading and impact loading is in the force position (four-point bending for cyclic loading and three-point bending for impact loading).

The steel burden used during the experiment consisted of a central pole and a main cylinder/hammer, which supports steel discs of different weights. The required weight was obtained by combination of the steel discs. 


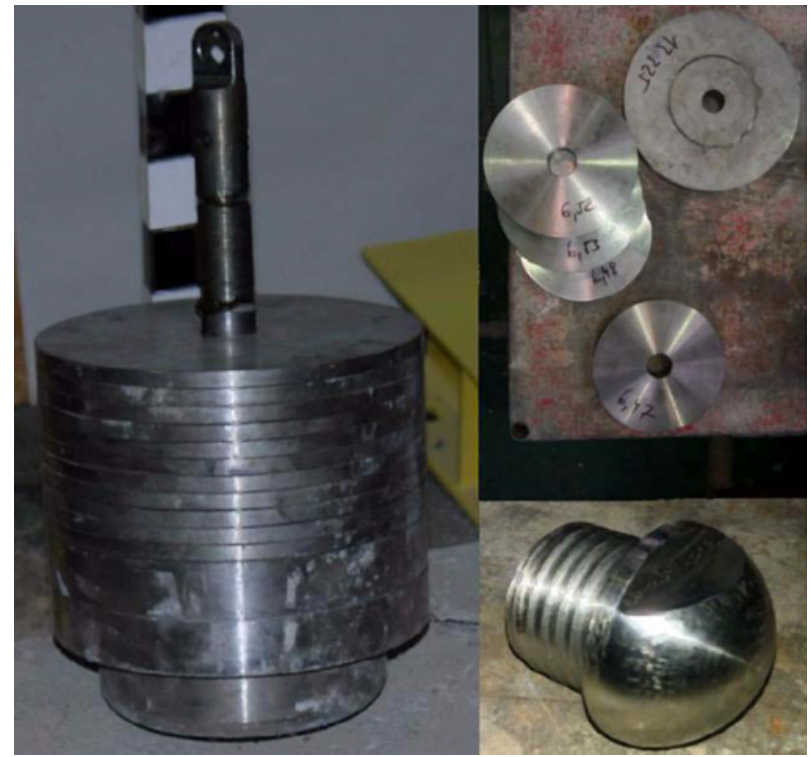

Figure 4. Steel burden, discs and hemispherical tip.

On the lower surface of the steel cylinder, a hemispherical tip $(\mathrm{R}=20 \mathrm{~mm})$ is placed, which concentrates the applied impact loading into one exact point. The burden used for the testing weights $90 \mathrm{~kg}$. The burden, discs and tip can be seen on Fig. 4.

\section{Interaction of the impact loading, fatigue and chemical deterioration}

The rebound hammer (as described in Sect. 2.4) was used for the testing of the influence of fatigue and chemical deterioration on the impact of RC specimens.

As mentioned before, as far in total 3 specimens were tested; specimen $\# 1$ - stored in dry condition, not exposed to cyclic loading; specimen \#2 - stored in dry condition, exposed to cyclic loading and specimen \#3 stored in acidic environment, exposed to cyclic loading. The specimens were made from the same concrete mix.

The fatigue loading resulted into an increase of deflections. The increase due to the deterioration caused by the aggressive environment was observed as well, but in smaller scale. It can be assumed that with the increase of strain rates (reflected by the dynamic increase factor (DIF)), can cause that the increase in deflection or damage will be higher for the deteriorated specimens. This assumption is based on the fact that the value of DIF increases along with the increase in strain rates. Thus the decrease in mechanical properties due to chemical deterioration of concrete can become more significant. Values of the DIF for the cyclic and impact testing were determined according to the standards for concrete, Eq. (1) - Model Code 1990 [8] and Eq. (2) - Model Code 2010 [9].

$$
\begin{gathered}
f_{c, i m p, k} / f_{c m}=\left(\dot{\varepsilon}_{c} / \dot{\varepsilon}_{c 0}\right)^{0.014} \text { for } \dot{\varepsilon}_{c} \leq 30 s^{-1} \\
f_{c t, i m p, k} / f_{c t m}=\left(\dot{\varepsilon}_{c t} / \dot{\varepsilon}_{c t 0}\right)^{0.018} \text { for } \dot{\varepsilon}_{c t} \leq 10 s^{-1} .
\end{gathered}
$$

Table 4. Specification of the fatigue testing settings.

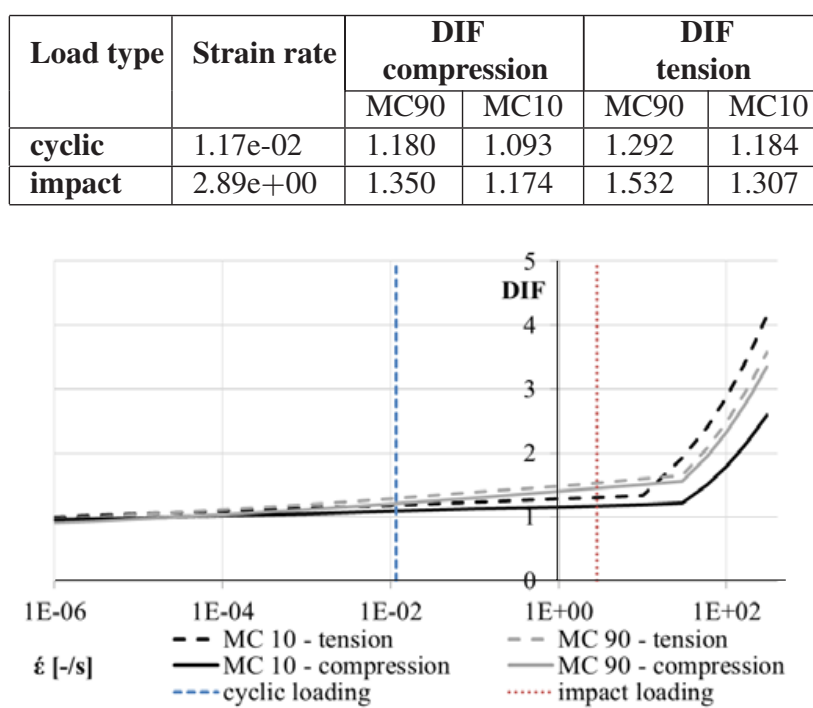

Figure 5. DIF according to MC90 [8] and MC10 [9].

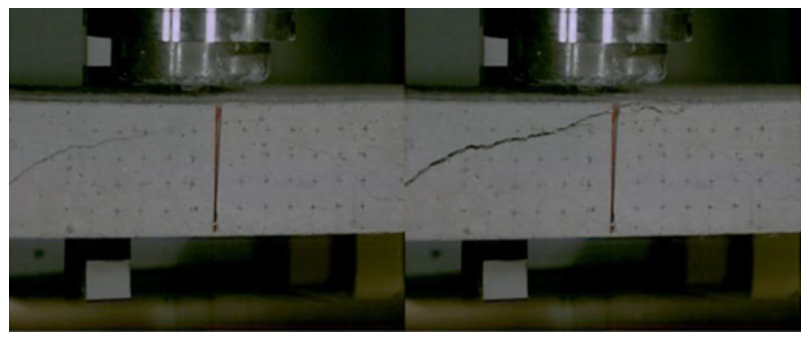

Figure 6. Two sample frames from the high-speed camera.

For both types of the testing, the DIF was evaluated on the base of the strain rates. The strain rate was calculated from the change of the specimen deflections in time; the scheme of the calculation is represented by Eq. (3).

$$
\Delta w(t) \rightarrow \Delta 1 / r(t) \rightarrow \dot{\varepsilon}
$$

The evaluated strain rates with corresponding values of DIF are listed in Table 4. The development of DIF as a function of different strain rates can be seen in Fig. 5. The results of the first run of tests are described further.

\subsection{First set of impact testing}

The decrease in instantaneous velocity within the impact together with the increase in deflections were chosen as a main factors for the evaluation of the specimens behaviour and resistance to impact loading. The experiment was recorded with high-speed camera with $10.000 \mathrm{fps}$. The video sequence was used for the evaluation of the behaviour. Two sample frames with time interval $1 \mathrm{~ms}$ can be seen in Fig. 6.

Results for the specimen \#1, not exposed to cyclic loading, are in Fig. 7.

After the impact (frame 12) the steep decrease in velocity can be observed. The absorbed energy is reflected in deflection increase. The impact lasts about $8 \mathrm{~ms}$ (each frame corresponds to $1 \mathrm{~ms}$ ). The shear cracks appeared similarly to the fatigue testing as can be seen on the Fig. 8 . 


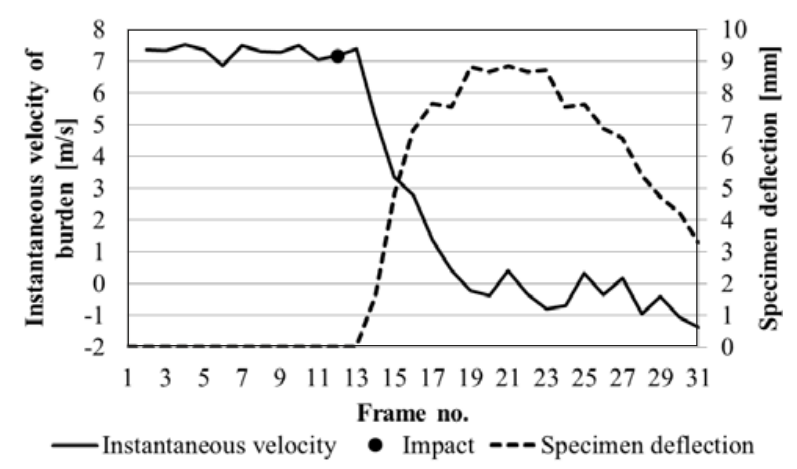

Figure 7. Development of burden velocity and specimen deflections during impact (specimen \#1).

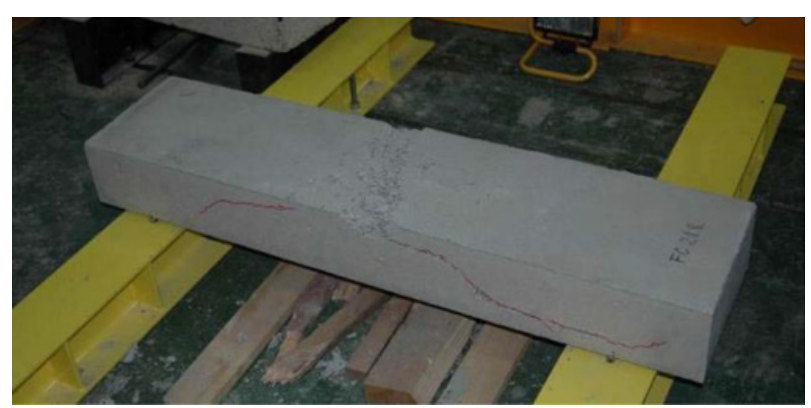

Figure 8. Condition of the specimen after impact (spec. \#1).

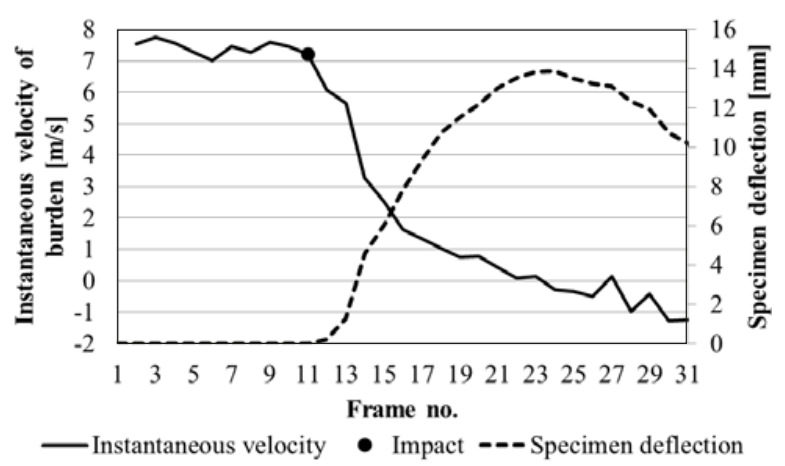

Figure 9. Development of burden velocity and specimen deflections during impact (specimen \#2).

After the rebound of the burden (velocities lower than 0) the specimen deflection partially decreased.

Results for the specimen \#2, exposed to cyclic loading, are in Fig. 9. The decrease in velocity after the impact is slower than for the specimen \#1. Shear cracks from the fatigue testing were opening, thus the energy was absorbed at slower rate, but with result of higher deflections. The impact lasts about $12 \mathrm{~ms}$. In comparison of the specimen \#1 and specimen \#2 the increase in deflections in impact loading due to the damage caused by fatigue testing is up to $40 \%$. Condition of the specimen \#2 after the impact loading can be seen in Fig. 10.

Results for the specimen \#3, chemically deteriorated specimen exposed to cyclic loading, can be found in Fig. 11. The decrease in velocity after the impact is slower than for the specimen \#1 and \#2. Shear cracks from the fatigue testing were opening and the deteriorated layers of concrete crushed in contact with the burden. Duration

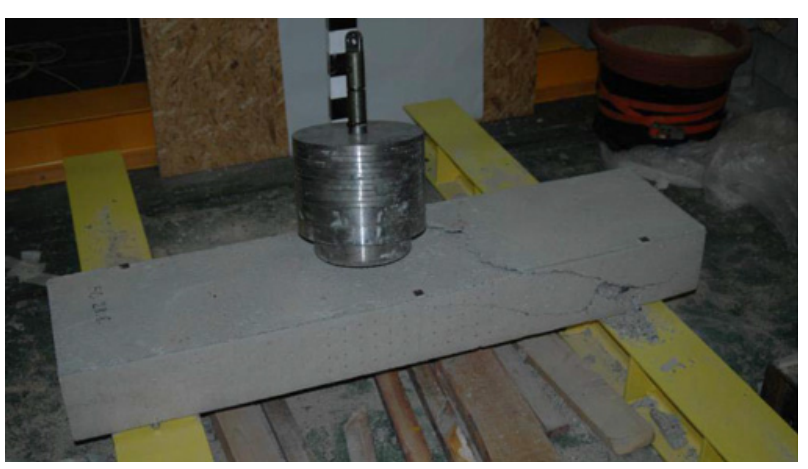

Figure 10. Condition of the specimen after impact (spec. \#2).

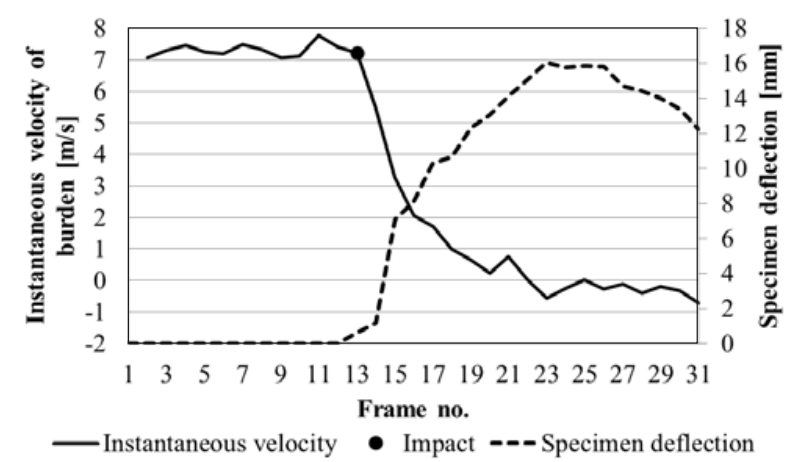

Figure 11. Development of burden velocity and specimen deflections during impact (specimen \#3).

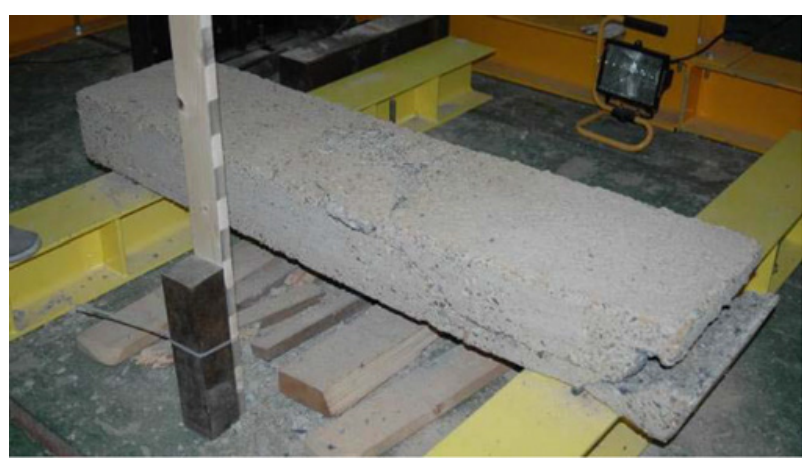

Figure 12. Condition of the specimen after impact (spec. \#3).

of the impact was about $14 \mathrm{~ms}$. In comparison of the specimen \#2 and specimen \#3 the increase in deflections in impact loading due to the damage caused by chemical deterioration is up to $15 \%$. When comparing the specimen $\# 1$ and \#3 the increase in deflections due to the combined deterioration due to fatigue and aggressive environment is up to $60 \%$. The specimen \#3 after the impact loading is in Fig. 12.

From the results depicted in Figs. 7, 9 and 11 preliminary conclusions can be drawn. The comparison between the behaviour of all three tested specimen from the viewpoint of the velocity or deflections can be seen on the Figs. 13, 14 respectively. The Figures depict only the time interval after the impact. The impacts last cca 8 , 12 and $14 \mathrm{~ms}$ respectively for the specimen \#1, \#2 and \#3. The assumed ends of the impacts are marked with points.

The differences in the decrease in the velocity of the specimens can be observed. The impact in case of 


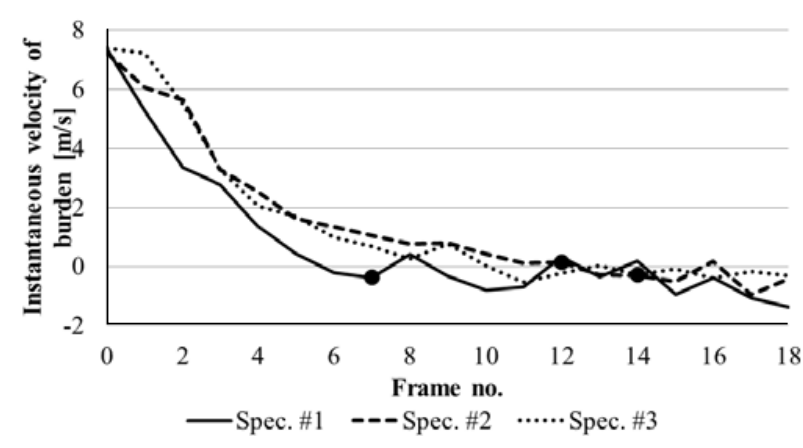

Figure 13. Comparison of the specimens in view of the velocity.

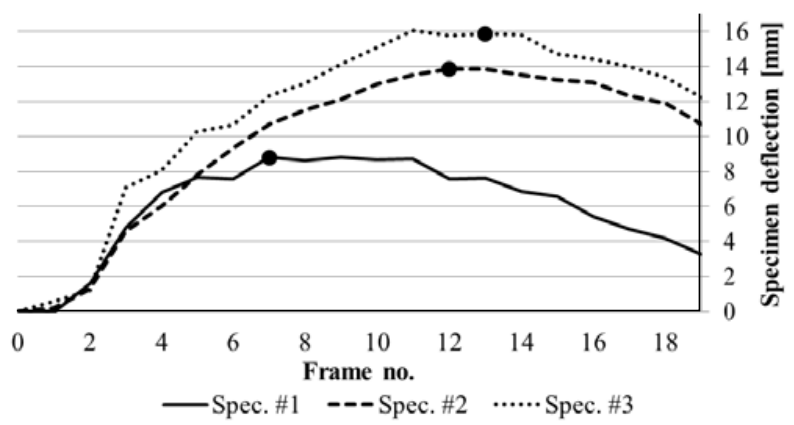

Figure 14. Comparison of the specimens in view of the velocity.

the specimen \#1 last only $8 \mathrm{~ms}$. After that the hammer rebounded and the velocity on the graph acquires negative values (movement against the direction of gravity). The impact interval of the specimens \#2 and \#3 last up to $75 \%$ longer (14 $\mathrm{ms}$ in case of specimen \#3).

The comparison with respect to deflections corresponds to the velocity comparison. The deflection of the specimen \#1 is significantly lower than in case of the other specimens.

The cracks development transforms the problem from the linear elasticity to the problem of the fracture mechanics and plasticity. It can be assumed that the behaviour of the specimens is affected by the fracture toughness. Furthermore it can be assumed that the fracture toughness of the specimens with partially damaged material matrix due to chemical deterioration or cyclic loading is lower, thus the energy required for the crack developing is lower as well.

The phenomenon of lower decrease in velocities of the specimens \#2 and \#3 can be explained due to the opening of the cracks in structure and microstructure of the specimens, which formed due to cyclic loading and the chemical deterioration. In the case of the specimen \#1 there can be assumed only micro cracks formed due to shrinkage and chemical processes during the hydration of the concrete. It can be assumed that these cracks occur in considerably lesser extent. Thus the propagation of the new cracks significantly increases the required energy.

The phenomenon of the higher deflection of the deteriorated specimens can be explained with an initial damage as well. The necessity for the formation of the new cracks highly absorbs the kinetic energy obtained during the impact. The initial increase in deflection (until $5^{\text {th }}$ frame) corresponds with the formation of visible shear

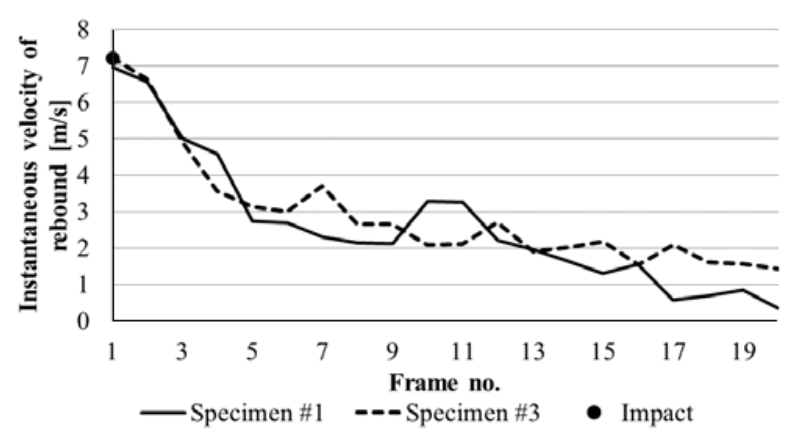

Figure 15. Results of the $2^{\text {nd }}$ impact loading - inst. velocity.

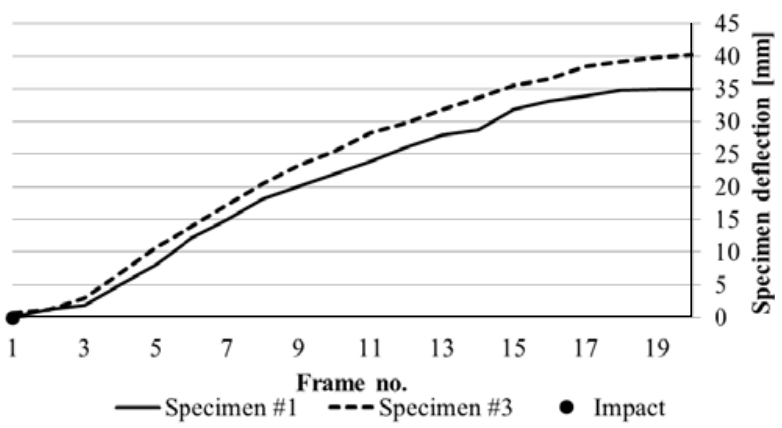

Figure 16. Results of the $2^{\text {nd }}$ impact loading - spec. deflections.

crack and its opening. For the specimen \#1 it is almost the only damage visible and from the graph it is obvious that this crack is dominant in the deflection value. In the case of the specimens \#2 and \#3 the shear crack opened and other cracks formed due to the cyclic loading or the chemical deterioration were further opening and developing. This results in the higher deflections and lower rate of the energy absorption.

\subsection{Residual resistance to the impact loading}

For the purposes of the residual resistance to the impact loading two additional impact loads were applied to the above mentioned specimens.

Due to technical difficulties, the video sequencing used for the evaluation was not triggered at each time, thus the results for the $2^{\text {nd }}$ and $3^{\text {rd }}$ impact loading of the specimen $\# 2$ and $3^{\text {rd }}$ impact loading for the specimen \#1 are not evaluated. Comparison for the behaviour of the specimens \#1 and \#3 during the second impact loading can be seen on Figs. 15 (instantaneous burden velocity) and 16 (specimen deflections). The graphs take into account only the interval of the impact.

As can be observed on the Figs. 13 and 14 the behaviour after the first impact loading is similar for the both specimens. The decrease in the velocities is slightly lower in the case of the specimen \#3 which corresponds with the higher cracks distribution in the specimen, thus lower rate of the energy absorption.

In case of the deflections the pattern is the same for both specimens. This is mainly due to the fact, that the specimens are already severely damaged especially in the tensile zone, thus the magnitude of deflections is primarily affected by the steel reinforcement, which is the same in both specimens $(6 \times \oslash 16$ B500B). The higher deflection 
of the specimen \#3 can be attributed to the coupled chemical and mechanical damage (due to the aggressive environment and cyclic loading) of the concrete matrix in compression.

\section{Conclusions}

The paper presented preliminary results of the on-going experimental program focused on the combined effect of the cyclic loading, deterioration due to aggressive environment and impact loading.

The exposure to the cyclic loading resulted in higher deflection under the impact loading (increase up to $40 \%$ ) and lower rate of the energy absorption. The specimen \#3 which was exposed to cyclic loading and the aggressive environment (360 days in solution of hydrochloric acid) exhibited even higher deflection (increase up to $15 \%$ compared to specimen \#2 and up to $60 \%$ compared to specimen \#1). The rate of energy absorption was lower as well. These phenomena can be explained by cracks in specimens after cyclic loading (shear cracks and micro cracks) and by the material matrix damage caused by the deteriorative chemical reactions due to aggressive environment.

The behaviour after the first impact loading has similar pattern for all the evaluated specimens. This can be attributed to the significant influence of the reinforcement, which was not affected by the cyclic loading or chemical deterioration.

For the proper quantification of the mentioned phenomena all the remaining specimens will be tested by rebound hammer impact loading in 2015.

The financial support of the Czech Science Foundation grant project 13-30441S is gratefully acknowledged.

\section{References}

[1] A. Alliche, Int. J. Fat., 26, 915-921 (2004)

[2] M. Foglar, Bridge Maintenance, Safety, Management and Life Extension, 3185-3189 (2010)

[3] Y. Chen, I.M. May, Struct. Build., 162, 45-46 (2009)

[4] CEN, Eurocode 1: Part 1-7 (Brussels, 2006)

[5] Y.F. Fan, Z.Q. Hu, Y.Z. Zhang, Const. Build. Mat., 24, 1975-1983 (2010)

[6] M.C. Chen, K. Wang, L. Xie, Eng. Fail. Anal., 27, 272-285 (2013)

[7] J. Göringer, M. Foglar, Adv. Mat. Res., 891, 494-499 (2014)

[8] fib, Model Code 1990 (Lausanne, 1993)

[9] fib, Model Code 2010 (Lausanne, 2010) 